2017-09-18

\title{
Alcohol and Road Traffic Injuries in Latin America and the Caribbean: A Case-Crossover Study
}

\author{
Borges, Guilherme
}

http://rpsico.mdp.edu.ar/handle/123456789/624

Descargado de RPsico, Repositorio de Psicología. Facultad de Psicología - Universidad Nacional de Mar del Plata. Inni 


\title{
Alcohol and Road Traffi c Injuries in Latin America and the Caribbean: A Case-Crossover Study
}

\author{
Guilherme Borges (D), Maristela Monteiro, Cheryl J. Cherpitel, Ricardo Orozco (D), Yu Ye, \\ Vladimir Poznyak, Margie Peden, Flavio Pechansky, Mariana Cremonte, Sandra D. Reid, and \\ Jesus Mendez
}

\begin{abstract}
Background: This study reports dose- response estimates for the odds ratio (OR) and population attributable risk of acute alcohol use and road traffi c injury (RTI).

Methods: Data were analyzed on 1,119 RTI patients arriving at 16 emergency departments (EDs) in Argentina, Brazil, Costa Rica, Dominican Republic, Guatemala, Guyana, Mexico, Nicaragua, Panama, and Trinidad and Tobago. Case-crossover analysis, pair-matching the number of standard drinks consumed within the 6 hours prior to the RTI with 2 control periods (prior d/wk), was performed using fractional polynomial analysis for dose- response.

Results: About 1 in 6 RTI patients in EDs were positive for self-reported alcohol 6 hours prior to the injury (country range 8.6 to $24.1 \%$ ). The likelihood of an RTI with any drinking prior (compared to not drinking) was 5 times higher (country range OR 2.50 to 15.00) and the more a person drinks the higher the risk. Every drink (12.8 g alcohol) increased the risk of an RTI by 13\%, even 1 to 2 drinks were associated with a sizable increase in risk of an RTI and a dose- response was found. Diff erences in ORs for drivers $(\mathrm{OR}=3.51 ; 95 \% \mathrm{CI}=2.25$ to 5.45$)$, passengers $(\mathrm{OR}=8.12 ; 95 \% \mathrm{CI}=4.22$ to 15.61$)$, and pedestrians $(\mathrm{OR}=6.30 ; 95 \% \mathrm{CI}=3.14$ to 12.64$)$ and attributable fractions were noted. Acute use of alcohol was attributable to $14 \%$ of all RTIs, varying from $7 \%$ for females to $19 \%$ for being injured as apassenger.

Conclusions: The finding that the presence of alcohol increases risk among drivers and nondrivers alike may further help to urge interventions targeting passengers and pedestrians. Routine screening and brief interventions in all health services could also have a beneficial impact in decreasing rates of RTIs. Higher priority should be given to alcohol as a risk factor for RTIs, particularly in Latin America and the Caribbean.
\end{abstract}

Key Words: Alcohol, Case-Crossover, Emergency Department, Risk, Road Traffi c Injury.

$\mathrm{G}$ LOBALLY, ROAD TRAFFIC injuries (RTIs) claim more than 1.2 million lives annually (World Health Organization, 2015a). They are estimated to be the ninth leading cause of death across all age groups (leading cause of

From the National Institute of Psychiatry Ramon de la Fuente (GB, RO), Mexico City, Mexico; Pan American Health Organization (PAHO) (MM), Washington, District of Columbia; Alcohol Research Group (CJC, YY), Emeryville, California; Department of Mental Health and Substance Abuse (VP), World Health Organization (WHO), Geneva, Switzerland; Department for the Management of Noncommunicable Diseases, Disability, Violence and Injury Prevention $(M P)$, World Health Organization (WHO), Geneva, Switzerland; Center for Drug and Alcohol Research (FP), Hospital de Clinicas de Porto Alegre- UFRGS/Federal University of Rio Grande do Sul, Porto Alegre, Brazil; Fac. Psicología - UNMDP (MC), Mar del Plata, Argentina; Caribbean Institute on Alcoholism and Other Drug Problems (SDR), Port of Spain, Trinidad \& Tobago; and Instituto sobre Alcoholismo y Farmacodependencia (JM), San Jose, Costa Rica.

Received for publication June 16, 2017; accepted July 31, 2017.

Reprint requests: Guilherme Borges and Ricardo Orozco, National Institute of Psychiatry Ramon de la Fuente, Calzada Mexico Xochimilco 101, Col. San Lorenzo Huipulco, Mexico City CP14370, Mexico. Tel.: +55-5255-41605334; Fax: +55-5255-56550411; E-mails: guibor@ imp.edu.mx_andric_oz@imp.edu.mx.

DOI: $10.1111 /$ acer. 13467 death among young people aged between 15 and 29 years) and are predicted to become the seventh leading cause of death by 2030 , costing governments approximately $3 \%$ of their gross domestic product (World Health Organization, 2015a). Data from the third Global Status Report on Road Safety show that low- and middle-income countries present double the fatality rates of high-income countries and account for $90 \%$ of all road traffi c deaths (World Health Organization, 2015a).

Current evidence from Latin America and the Caribbean (LAC) suggests that alcohol is an important component of the global burden of disease in the region (Latin America and Caribbean- World Bank Region), with a great impact on noncommunicable diseases and injuries (Institute for Health Metrics and Evaluation [IHME], 2015; Monteiro, 2007; Pan American Health Organization, 2015; World Health Organization, 2014). When examining where the impact of alcohol lies, a heavy burden is seen for injuries and, among these, for RTIs (motor vehicle crashes and deaths). Most of this burden is associated with alcohol use among males $(2.12 \%$ of all disability-adjusted life years (DALY) than among females (0.47\% of all DALY) (http:// ihmeuw.org/3udw; http://ihmeuw.org/3udx). The World Health Organization (WHO) estimated that $13 \%$ of all 
DALYS for RTIs was attributable to alcohol (World Health Organization, 2014). It is well established that drinking alcohol increases the risk of a traffi c crash (Cherpitel et al., 2015a; Krager et al., 1995; Taylor et al., 2010). Evidence of this link is also available for some countries in the region (Pechansky et al., 2010), as well as data suggesting that alcohol-related road traffic deaths reduce the life expectancy (Andreuccetti et al., 2012; Borges et al., 2013; Chandran et al., 2013; Saldanha et al., 2014; Ye et al., 2013b) and increase years of life lost (Andreuccetti et al., 2013; Sousa et al., 2010).

While there is evidence from high-income countries on the important contribution of alcohol use in RTIs and death (Beasley and Beirness, 2012; Berning et al., 2015; Houwing et al., 2011), local research on the relationship between alcohol and RTIs providing prevalence data, relative risk estimates, and alcohol attributable fractions for this association in LAC is scarce or simply lacking. Some countries, such as Brazil (Gjerde et al., 2015), have contributed a large number of research studies (Pechansky et al., 2010), but for most countries the evidence is scattered and not comparable. Most importantly, there is a paucity of evidence on the presence of alcohol in RTIs among pedestrians and nondriver riders, who are important victims of RTIs (Forson et al., 2016; Maximus et al., 2016; du Plessis et al., 2016; Senserrick et al., 2014; Sethi et al., 2016; Waller et al., 1986).

Our goal is to report the risk of an RTI when drinking prior to the event and population attributable risk (PAR) for cases of RTI from 10 countries of the LAC (Argentina, Brazil, Costa Rica, Dominican Republic, Guatemala, Guyana, Mexico, Nicaragua, Panama, and Trinidad and Tobago) using a case-crossover design (Borges et al., 2006, 2013) with a new approach to estimate dose- response curves and attributable fractions (Cherpitel et al., 2015a,b) for this population. The case-crossover design is especially suited for studying the impact of a transient exposure (such as alcohol and drug use, i.e., substance use) on an acute outcome (such as an RTI) (Maclure, 1991; Mittleman et al., 1995), in which an individual is used as his own control and generates data that can be used in dose- response models that do not assume a specific form or shape of the dose- response.

\section{MATERIALS AND METHODS}

\section{Sample}

The methods for this case-crossover study are similar to those used previously in emergency department (ED) studies from the World Health Organization (2009), Collaborative Study on Alcohol and Injury (Borges et al., 2006), and the Pan American Health Organization (PAHO; 2013) study in EDs (Borges et al., 2013) that reported on the risk of alcohol use and injury. In all studies, probability samples of patients aged 18 years and older who arrived at the ED within 6 hours of the injury event were obtained by approaching consecutive arrivals to each ED, with equal representation of each shift for each day of the week. Further details on the general methodology, questionnaire development, and training for the WHO study and the associated PAHO study can be found elsewhere (Borges et al., 2013; Cherpitel et al., 2006; World Health Organization, 2009). For this study, only patients from LAC attending the ED, who reported their cause of injury as a result of a road traffi c crash ("Hit by vehicle," "Collision as driver," or "Collision as passenger"), were included. The following study sites contributed with cases: Argentina (2001), Brazil (2001), Costa Rica (2012 to 2013), Dominican Republic (2010), Guatemala (2011), Guyana (2011), Mexico (2002), Nicaragua (2010), Panama (2010), and Trinidad and Tobago (2015). Ethical approval was obtained from institutional review boards in each participating country, and the WHO and PAHO Ethics Review Committee.

\section{Alcohol Use}

The interview included questions on whether the participant reported drinking during the 6 hours before the RTI, the same 6 hour period in the previous week (all sites), and the same time of day on the day prior to injury (all sites except Argentina and Brazil). For alcohol use during the 6 hours prior to the RTI, patients were asked: "In the 6 hours before and up to you having the RTI, did you have any alcohol to drink, even one drink?" (yes/no). Information on alcohol use at the same time in the previous week was elicited as follows: 'In this next section, I am going to ask you about what you were doing exactly 1 week ago. Think about the time you had your RTI (today) and remember the same time a week ago. Last week at the same time, did you have any alcohol to drink in the 6 hours leading up to this time?" (yes/no). Parallel questions were asked for the day prior to the injury. If patients reported drinking prior to the RTI or in the prior week or the prior day, they were asked the beverage-specific number and size of containers consumed in the relevant 6-hour period prior to the RTI. The volume of alcohol consumed during the 6-hour period was analyzed by converting the number and size of drinks of wine, beer, spirits, and local beverages to pure ethanol, and summing across beverage types, using a standard drink size of $16 \mathrm{ml}(12.8 \mathrm{~g})$ as a common volume measure across beverages.

\section{Data Analysis}

Patients who reported drinking at any time within the 6 hours prior to RTI were considered exposed cases. The multiple pairmatching approach compared the reported use of alcohol of each patient during the 6 hours prior to the RTI with their respective use of alcohol during the same time period on the same day in the previous week and the same time of day on the day prior to injury (when available for the site). Conditional logistic regression was used to calculate matched-pair odds ratios (ORs) and 95\% confidence intervals (CIs) (Rothman et al., 2008). Three models were calculated: 1 with alcohol prior as a dichotomous exposure, and 2 with alcohol volume as continuous: linear and polynomial. Variations in the magnitude of the OR across levels of fixed characteristics (study site, sex, age, type of RTI) were examined using the chi-square test of homogeneity (Rothman et al., 2008). The analysis of dose- response relationship between the amount of drinking 6 hours prior and the RTI using fractional polynomial and calculations of alcohol attributable fractions, or PAR, is explained in full detail in 2 prior works from our group (Cherpitel et al., 2015a,b). Briefly, this approach circumvents the more traditional use of preset cut-points that are somehow arbitrary (e.g., 1 to 10 drinks, 11 to 20 drinks). While the use of preset cut-points does not assume any prespecified dose- response shape (exponential, quadratic, etc.), it presupposes that there may be abrupt changes in the OR of RTI from 1 to 10 drinks to 11 to 20. As an alternative to categorical step-functions, fractional polynomials have recently been used to estimate the alcohol and injury dose- response relationship in a systematic review and metaanalysis of articles reporting acute alcohol dose- response data (Taylor et al., 2010). Models were fitted using the STATA version 13.1 
(Stata Corp LP, 2013) fracpoly command. Royston and colleagues (1999) provide details of model fitting as well as estimation of analytic 95\% CIs. PAR was calculated based on the OR estimates, evaluating the fractional polynomial function at the observed mean volume for a given range of drinks, by the prevalence of drinking 6 hours prior in that range: $\mathrm{PAR}_{\mathrm{i}}=$ Prevalence $_{\mathrm{i}} 9\left(1-1 / \mathrm{OR}_{\mathrm{i}}\right)$ (Steenland and Armstrong, 2006). The total PAR was computed as

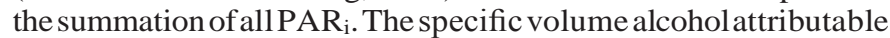
fraction (SVAAF) or PAR is interpretable as the proportion of RTIs that is attributable to alcohol drinking at a particular drinking level, with $95 \%$ CIs for this proportion.

\section{RESULTS}

Table 1 presents the number of patients arriving at each ED by country and the percentage that arrived because of an RTI. In total, almost 1 in every 5 injury patients was treated for an RTI, ranging from a low $9.6 \%$ in Mexico to a high $43.9 \%$ in the Dominican Republic. Of those patients arriving because of an RTI, $17.3 \%$ reported alcohol use 6 hours prior to the crash, ranging from a low $8.6 \%$ in Costa Rica to a high $24.1 \%$ in Argentina. For the total sample of patients with an RTI (data not shown), about $27 \%$ were females and $73 \%$ reported working at least 30 hours a week, had a mean age of 29 years, and had a mean of 10 years of formal education. The distribution of type of motor vehicle injury was as follows: $25.1 \%$ were hit by a vehicle (range 14.6 to $35.4 \%$ ), $47 \%$ had a collision as a driver (range 31.8 to $56.7 \%$ ), and $27.9 \%$ reported a collision as a passenger (range 20.9 to $47.6 \%)$.

Table 2 presents the OR estimates for dichotomous exposure (alcohol yes/no) by selected key variables, together with homogeneity tests. The use of alcohol 6 hours prior to the RTI increased the risk by 5.07 times for the total sample. Examination of changes in these ORs by country suggested that while they varied from a low 2.50 (in Costa Rica) to a high 15.00 (in Argentina), these ORs are homogenous (by the homogeneity test); that is, these country-specific ORs are conceptually the same and the variation across countries is just random. Demographic variables (sex and age) did not modify the eff ect; the type of motor vehicle injury had a bor- derline significance, suggesting the need for inspecting the dose- response curves more closely. "Collision as driver" had the lowest OR, followed by "hit by vehicle" and "collision as passenger."

Table 3 presents the dose- response estimates for alcohol use and all RTIs for up to 60 drinks. The number of drinkers at each consumption level ranged from 8 to 45 , and the prevalence at each consumption level ranged from $0.70 \%$ up to $4.02 \%$. First, even 1 to 2 drinks increased the likelihood of an RTI, with an OR $=3.87,95 \% \mathrm{CI}=(2.77$ to 5.41$)$, and the OR for up to 60 drinks was 26.50 (6.93 to 101.33). In some instances, the confidence intervals were wide, reflecting the fact that even with such large sample size, there are few discordant pairs for specific levels of drinking. The corresponding graph of these ORs (Fig. 1) suggests a monotonic increase in risk of RTI with more alcohol consumption. Table 3 also presents the corresponding SVAAF or PAR associated with these drinking levels. It is noteworthy that while the lower categories of drinking have comparatively lower ORs, these categories have a large number of RTI cases and a similar or sometimes higher prevalence of exposure and PARs that are comparable with those of higher number of drinks. The highest PAR is of the category " 2.1 to 4 drinks." Across levels of drinking, the summation of PARs implies that the elimination of alcohol would reduce RTIs by about $14 \%$.

We examined the dose- response curves by sex, age, and type of RTI. Curves were similar for sex and age groups (not shown) but varied by type of RTI (Fig. 2), with a very sharp increase in risk at low levels of consumption for "hit by vehicle," followed by high slopes for "collision as passenger" and a plateau after 8 drinks for "hit by a vehicle." While ORs were homogeneous across diff erent groups, large variations were observed of PAR for these categories: males: $17.33 \%$; females: $7.15 \%$; 18 to 30 years old: $15.36 \%$; 31 and over: $13.48 \%$; hit by vehicle: $14.93 \%$; collisions as driver: $11.12 \%$; collision as passenger: $19.35 \%$.

Table 1. Road Traffic Injury in Latin American and Caribbean EDs (10 Countries; 16 EDs)

\begin{tabular}{|c|c|c|c|c|c|c|c|}
\hline \multirow[b]{2}{*}{ Country } & \multicolumn{4}{|c|}{ Total sample } & \multicolumn{3}{|c|}{ Type of RTI among RTI cases } \\
\hline & Sample & $\begin{array}{c}\text { Road traffic } \\
\text { injuries }\end{array}$ & $\begin{array}{c}\% \text { Road traffic } \\
\text { injuries }\end{array}$ & $\begin{array}{c}\% \text { Self-report } \\
\text { alcohol use } \\
\text { before RTI injuries }\end{array}$ & $\begin{array}{l}\% \text { Hitby } \\
\text { vehicle }\end{array}$ & $\begin{array}{l}\text { \% Collision } \\
\text { as driver }\end{array}$ & $\begin{array}{c}\% \text { Collision as } \\
\text { passenger }\end{array}$ \\
\hline Argentina & 452 & 104 & 23.0 & 24.1 & 20.2 & 56.7 & 23.1 \\
\hline Brazil & 496 & 82 & 16.5 & 12.7 & 35.4 & 42.7 & 22.0 \\
\hline Costa Rica & 1,013 & 211 & 20.8 & 8.6 & 20.4 & 56.4 & 23.2 \\
\hline Dominican Republic & 501 & 220 & 43.9 & 18.8 & 23.2 & 55.9 & 20.9 \\
\hline Guatemala & 513 & 120 & 23.4 & 21.1 & 35.0 & 38.3 & 26.7 \\
\hline Guyana & 485 & 86 & 17.7 & 20.6 & 33.7 & 32.6 & 33.7 \\
\hline Mexico & 456 & 44 & 9.6 & 17.1 & 25.0 & 31.8 & 43.2 \\
\hline Nicaragua & 518 & 110 & 21.2 & 21.0 & 30.0 & 40.0 & 30.0 \\
\hline Panama & 490 & 103 & 21.0 & 20.4 & 14.6 & 37.9 & 47.6 \\
\hline Trinidad and Tobago & 252 & 39 & 15.5 & 18.7 & 18.0 & 48.7 & 33.3 \\
\hline Total & 5,176 & 1,119 & 21.6 & 17.3 & 25.1 & 47.0 & 27.9 \\
\hline
\end{tabular}

ED, emergency department; RTI, road traffic injury. 


\section{DISCUSSION}

To summarize, 1 in every 5 injury patients in EDs in LAC presented with an RTI, and 1 in every 6 RTI patients were positive for alcohol 6 hours prior to the event. The likelihood

Table 2. Matched-Pair Analysis of Any Alcohol Use Before Road Traffic Injury and the d/wk Prior in Latin American and Caribbean EDs $(n=1,119)^{a}$

\begin{tabular}{|c|c|c|c|c|c|c|}
\hline & \multirow[b]{2}{*}{ Valid $N$} & \multirow[b]{2}{*}{ OR } & \multirow[b]{2}{*}{$95 \% \mathrm{Cl}$} & \multicolumn{3}{|c|}{$\begin{array}{l}\text { Homogeneity } \\
\text { test }\end{array}$} \\
\hline & & & & $v^{2}$ & df & $p$ \\
\hline Total & 1,089 & 5.07 & 3.68 to 6.98 & - & - & - \\
\hline \multicolumn{7}{|l|}{ Country } \\
\hline Argentina & 101 & 15.00 & 1.98 to 113.56 & 9.49 & 9 & 0.394 \\
\hline Brazil & 79 & 3.50 & 1.15 to 10.63 & & & \\
\hline Costa Rica & 209 & 2.50 & 1.07 to 5.83 & & & \\
\hline Dominican & 214 & 3.55 & 1.91 to 6.59 & & & \\
\hline \multicolumn{7}{|l|}{ Republic } \\
\hline Guatemala & 119 & 12.03 & 4.20 to 34.44 & & & \\
\hline Guyana & 84 & 4.80 & 1.52 to 15.13 & & & \\
\hline Mexico & 44 & 3.14 & 0.76 to 13.00 & & & \\
\hline Nicaragua & 105 & 8.58 & 1.85 to 39.71 & & & \\
\hline Panama & 95 & 6.05 & 2.43 to 15.09 & & & \\
\hline $\begin{array}{l}\text { Trinidad and } \\
\text { Tobago }\end{array}$ & 39 & 9.29 & 2.02 to 42.68 & & & \\
\hline \multicolumn{7}{|l|}{ Sex } \\
\hline Female & 292 & 4.78 & 2.00 to 11.42 & 0.04 & 1 & 0.841 \\
\hline Male & 791 & 5.26 & 3.72 to 7.45 & & & \\
\hline \multicolumn{7}{|l|}{ Age category } \\
\hline Age $31+$ & 477 & 5.60 & 3.31 to 9.49 & 0.23 & 1 & 0.631 \\
\hline Age 18 to 30 & 600 & 4.76 & 3.18 to 7.14 & & & \\
\hline \multicolumn{7}{|c|}{ Type of road traffic injury } \\
\hline Hit by vehicle & 271 & 6.30 & 3.14 to 12.64 & 5.00 & 2 & 0.082 \\
\hline Collision as driver & 512 & 3.51 & 2.25 to 5.45 & & & \\
\hline $\begin{array}{l}\text { Collision as } \\
\text { passenger }\end{array}$ & 306 & 8.12 & 4.22 to 15.61 & & & \\
\hline
\end{tabular}

OR, odds ratio; $\mathrm{Cl}$, confidence interval; df, degrees of freedom.

${ }^{\text {a }}$ Patients with missing information on any alcohol use the injury day and the control period (Argentina and Brazil) or in both control periods (all other) were not used in the analysis. of an RTI after any drinking was 5 times higher (compared to not drinking), and the more a person drank, the higher the risk. For each drink, there was a $13 \%$ increased risk, and alcohol use prior to RTI was responsible for $14 \%$ of all RTIs, varying from $7 \%$ for females to $19 \%$ for being injured as a passenger. Diff erences in ORs and attributable fractions for drivers, passengers, and pedestrians were noted. Our find- ing of a PAR of $14.45 \%$ for RTI is consistent with prior studies from non-LAC samples (Cherpitel et al., 2015b; Kuendig et al., 2008; World Health Organization, 2014).

The high OR (5.07) result for any drinking from our sample of LAC patients may be due to the high frequency of heavy episodic drinking characterizing the LAC region (Pan American Health Organization, 2015), even at low levels of overall per capita consumption. Unfortunately, our sample

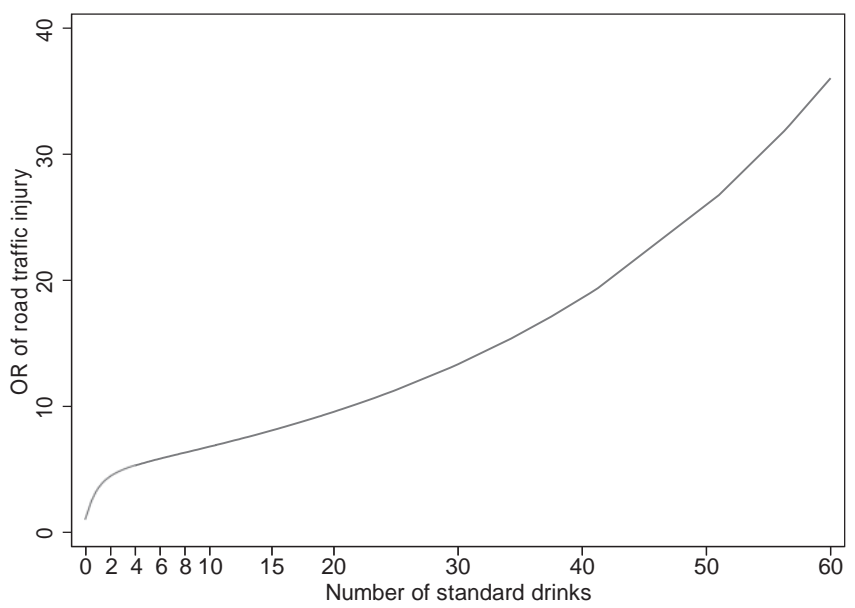

Fig. 1. Odds ratios of road traffic injury by alcohol volume consumed before injury. Best fit polynomial model with powers $-2,1$. Volume capped to 60 drinks (10 measures).

Table 3. Alcohol Odds Ratios (ORs and Attributable Fraction (AF) Estimates by Levels of Alcohol Consumed 6 Hours Before Road Traffic Injury and the $\mathrm{d} /$ wk Prior in Latin American and Caribbean EDs $(n=1,074)$

\begin{tabular}{|c|c|c|c|c|c|c|}
\hline \multicolumn{3}{|c|}{ Alcohol intakebefore injury ${ }^{a, f}$} & \multicolumn{2}{|c|}{ Odds ratios ${ }^{c}$} & \multicolumn{2}{|c|}{ Attributable fraction ${ }^{d}$} \\
\hline Range & $n$ & Prevalence $^{b}$ & OR & $95 \% \mathrm{Cl}$ & $A F$ & $95 \% \mathrm{Cl}$ \\
\hline No drinking & 882 & - & 1 & - & - & - \\
\hline$\leq 2$ & 37 & 3.38 & 3.87 & 2.77 to 5.41 & 2.50 & 1.42 to 3.58 \\
\hline 2.1 to 4 & 45 & 4.02 & 4.96 & 3.43 to 7.17 & 3.21 & 2.03 to 4.38 \\
\hline 4.1 to 6 & 26 & 2.36 & 5.53 & 3.82 to 8.00 & 1.94 & 1.03 to 2.83 \\
\hline 6.1 to 8 & 16 & 1.41 & 6.00 & 4.16 to 8.66 & 1.18 & 0.49 to 1.86 \\
\hline 8.1 to 10 & 8 & 0.70 & 6.54 & 4.51 to 9.49 & 0.59 & 0.11 to 1.07 \\
\hline 10.1 to 15 & 16 & 1.48 & 7.30 & 4.91 to 10.84 & 1.28 & 0.56 to 1.99 \\
\hline 15.1 to 30 & 27 & 2.49 & 9.52 & 5.63 to 16.09 & 2.23 & 1.29 to 3.16 \\
\hline 30.1 to 60 & 17 & 1.59 & 26.50 & 6.93 to 101.33 & 1.53 & 0.77 to 2.28 \\
\hline Total $^{e}$ & 1,074 & 17.43 & - & - & 14.45 & - \\
\hline
\end{tabular}

$\mathrm{Cl}$, confidence interval.

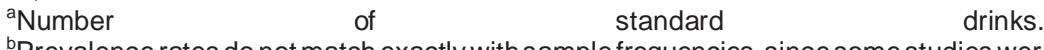

${ }^{\mathrm{b} P}$ revalence rates do not match exactly with sample frequencies, since some studies were weighted.

${ }^{\circ}$ Odds ratios are fractional polynomial estimates based on the mean volume of each volume category (e.g., 1.36 drinks for the $(0,2]$ range).

${ }^{d}$ Specific volume alcohol attributable fraction (SVAAF) $=P_{i} 9\left(1-1 / R R_{i}\right)$ in which $P_{i}$ is the prevalence of drinking at a given volume among total injured patients (cases) and $R R_{i}$ the odds ratios of injury for a given volume compared to no drinking.

'The total includes the sum of the prevalence and SVAAF across dose levels.

'Measures were capped to 60 drinks.

Matched OR from linear model with capped volume $=1.13 ; 95 \% \mathrm{Cl}=(1.09$ to 1.18$)$. 


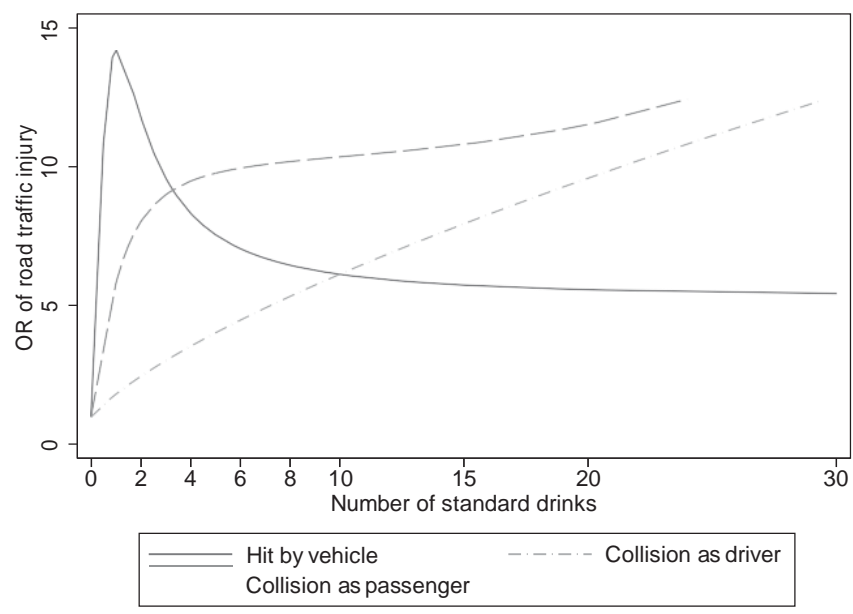

Fig. 2. Odds ratios of road traffic injury by alcohol volume consumed before injury, by type. $X$-axis trimmed to 30 drinks.

size per study site is too small for studying variations in ORs by study site by age/sex or drinking level, but prior studies from Cherpitel and colleagues (2015a) on possible eff ects of a country-level drinking pattern determined by WHO country's detrimental drinking pattern (Rehm et al., 2001) show that countries with the most detrimental drinking patterns may have increased alcohol attributable fractions for injuries compared to countries with a lower detrimental drinking pattern. The finding that at low and middle levels of drinking there is extensive PAR, brings attention to population measures for all drinkers and not only those with alcohol use disorders, as stated before (Poikolainen et al., 2007).

One of the few studies to separate RTI by type reported an OR of 5.2 and PAR of $24 \%$ for motor vehicle injury after drinking, but a high OR of 9.5 and high PAR of 39\% for pedestrians (Miller and Spicer, 2012). Our study documents for the first time in the LAC region that while an important part of RTIs are due to drivers using alcohol, passengers and pedestrians involved in road traffi c crash also contribute significantly to the burden of RTI. They comprise more than $50 \%$ of the cases, have considerable OR of an injury if drinking, and have even higher PAR than the drivers.

Prior eff orts to estimate the role of alcohol in RTI in the LAC region exist (Christophersen et al., 2016), but translating data to the need for intervention to both policy makers and the population at large has proven to be difficult (Pechansky and Chandran, 2012; Pechansky et al., 2016). The recently approved Decade of Action for Road Safety calls on member states to take the necessary steps to make their roads safer (World Health Organization, 2010a), and the 2030 Agenda on Sustainable Development Goals, set a goal of reducing road traffic deaths and injuries by $50 \%$ by 2020 (World Health Organization, 2015b). To accomplish these goals, measures to decrease modifiable risk factors, such as alcohol use before driving, are essential. Comparable data across a large number of LAC countries and the findings of this study showing that the presence of alcohol increases risk among drivers and nondrivers alike may further help to drive interventions targeting passengers and pedestrians. Data now exist to show that public health measures centered exclusively on drink-drivers are inadequate since they may miss about half of the cases of alcoholinvolved RTI in the LAC region.

The diff erences in the risk curves by type of RTI that we reported should be investigated further. While we know experimentally the influence of alcohol on motor coordination of drivers, we know very little on how alcohol aff ects time reaction, judgment, and impulsive behavior among pedestrians or passengers. Further studies on the diff erent risk curves reported here by type of RTI are, however, important, as we cannot rule out that our limited sample size for each type of RTI produced unstable estimates that may have driven these curves apart. Delving into the coalescence of other risk factors that put passengers and pedestrians at high risk of RTI is beyond the scope of the current report, but a common and potentially preventable risk is the consumption of alcohol.

\section{Limitations}

This study is limited to analysis of data from a representative sample of patients with RTI who attended specific EDs during a large time frame (2001 to 2015). Data from each country are most representative of the time period of data collection and current proportion of alcohol use, proportion of RTI, and potentially the SVAAF/PAR would have been impacted by socioeconomic/transportation and infrastructure development, alcohol policy, and cultural changes in each country during the total time period. Cases cannot be assumed to be representative of other individuals suff ering an RTI who did not seek medical attention and may be of lesser severity. In the LAC region, motorcycle crashes account for a sizable proportion of the motor vehicle injuries as a driver, and they have been reported with high prevalence of alcohol and cannabis (Longo et al., 2000), but we lack this information. All analyses reported here are based on the patient's reported alcohol consumption across diff erent times, which may not be evenly accurate, thereby producing an overestimate of the association between alcohol and RTI for case-crossover studies. Findings using control periods other than drinking during the previous week have been mixed, suggesting either higher estimates (Borges et al., 2004; Gmel and Daeppen, 2007), lower estimates (Borges et al., 2013), or no diff erential report (Ye et al., 2013a). While our approach of multiple matching aimed to reduce such bias, if present at all, this is a topic for further research. Biological measures of blood alcohol content at time of injury are desirable, and the WHO-PAHO studies include such, but there are no biological measures available for the control periods. Despite the fact that case-crossover studies are well suited to control for between-person confounders, they do not remove the possibility that within-person confounders (such as use of 
safety belt) may exist. Other variables, such as street illumination and presence of pedestrians' bridges or sidewalks, may also have played a role in RTI, but are beyond the scope of this research. Importantly, new research should include substances other than alcohol and estimate ORs for combinations of drugs and alcohol on RTI (Gjerde et al., 2015; Strand et al., 2016). This is the largest case-crossover study reported to date, but our sample size was still insuffi cient to perform analyses by gender or age groups or by study site, and the dose- response estimates are unstable, especially for the higher consumption categories.

\section{CONCLUSION}

Despite these limitations, this is one of the largest studies ever reported on acute alcohol use and RTI with data coming from a large sample of patients from several countries of LAC. Alcohol was found among 1 in every 6 RTI cases (drivers, passengers, and pedestrians alike), and reducing consumption even at low and middle levels ( $\leq 4$ drinks) can have a sizable impact on risk and population burden. Measures to reduce alcohol consumption among drivers, passengers, and pedestrians involved in RTI, within the scope of global and local strategies to reduce alcohol consumption (World Health Organization, 2010b), is a step that should not be postponed in LAC.

\section{ACKNOWLEDGMENTS}

The paper is based, in part, on data collected by the following collaborators participating in the World Health Organization and implemented by the WHO Collaborative Study Group on Alcohol and Injuries under the direction of V. Poznyak and M. Peden (WHO, Switzerland): G. Borges (Mexico); M. Cremonte (Argentina); N. Figlie and R. Larajeira (Brazil). A list of other staff contributing to the project can be found in the Main Report of the Collaborative Study on Alcohol and Injuries, WHO, Geneva. The paper is also based on work performed by collaborators participating in the Pan American Health Organization Collaborative Study on Alcohol and Injuries, directed by M. Monteiro (PAHO, USA) in coordination with C. J. Cherpitel (USA) and G. Borges (Mexico). It was implemented at country level by the following lead investigators: V. Aparicio and A. de Bradshaw (Panama); V. Lopez (Guatemala); M. Paltoo (Guyana); E. Perez (Dominican Republic); D. Weil (Nicaragua). We also acknowledge Julio Bejarano (Costa Rica) and Sandra Reid (Trinidad and Tobago). The authors alone are responsible for views expressed in this paper, which do not necessarily represent those of the other investigators participating in the WHO or PAHO collaborative studies on alcohol and injuries, nor the views or policy of the World Health Organization or the Pan American Health Organization.

\section{FUNDING}

This study was supported in part by the Pan American Health Organization, the government of Valencia, Spain, and World Health Organization. And this study was supported in part by a grant from the U.S. National Institute on Alcohol Abuse and Alcoholism (NIAAA) (R01 5 AA013750) and Instituto Nacional de Psiquiatria Ramon de la Fuente Muñiz.

\section{CONFLICT OF INTEREST}

None declared.

\section{REFERENCES}

Andreuccetti G, Carvalho HB, Korcha R, Ye Y, Bond J, Cherpitel CJ (2012) A review of emergency room studies on alcohol and injuries conducted in Latin America and the Caribbean region. Drug Alcohol Rev 31:737- 746.

Andreuccetti G, Gawryszewski V, Diehl A, Monteiro M, Cherpitel CJ (2013) Alcohol's causal role in interpersonal violence and road traffi c injuries in the Americas, in Prevention of Alcohol-Related Injuries in the Americas: From Evidence to Policy Action (Cherpitel CJ, Borges G, Giesbrecht N, Monteiro M, Stockwell T eds), pp 27-35. Pan American Health Organization, Washington, DC.

Beasley EE, Beirness DJ (2012) Alcohol and Drug Use Among Drivers Following the Introduction of Immediate Roadside Prohibitions in British Columbia: Findings from the 2012 Roadside Survey Final Report, October 2012. Beirness \& Associates, Inc., Ottawa, ON. Available at: http:// www2.gov.bc.ca/assets/gov/driving-and-transportation/driving/publications/ bc-roadside-report2012.pdf. Accessed September 3, 2017.

Berning A, Compton R, Wochinger K (2015) Results of the 2013-2014 National Roadside Survey of alcohol and drug use by drivers. Traffi c Safety Facts Research Note. Report No. DOT HS 812118 ed. HTSA, Washington, DC

Borges G, Cherpitel CJ, Mondragón L, Poznyak V, Peden M, Gutierrez I (2004) Episodic alcohol use and risk of nonfatal injury. Am J Epidemiol 159:565- 571.

Borges G, Cherpitel CJ, Orozco R, Bond J, Ye Y, MacDonald S, Rehm J, Poznyak V (2006) Multicentre study of acute alcohol use and non-fatal injuries: data from the WHO collaborative study on alcohol and injuries. Bull World Health Organ 84:453- 460.

Borges G, Orozco R, Monteiro M, Cherpitel CJ, Then EP, Lopez VA, Bassier-Paltoo M, Weil DA, Bradshaw AM (2013) Risk of injury after alcohol consumption from case- crossover studies in five countries from the Americas. Addiction 108:97-103.

Chandran A, Kahn G, Sousa T, Pechansky F, Bishai DM, Hyder AA (2013) Impact of road traffic deaths on expected years of life lost and reduction in life expectancy in Brazil. Demography 50:229-236.

Cherpitel CJ, Bond J, Ye Y, Borges G, Room R, Poznyak V, Hao W (2006) Multi-level analysis of causal attribution of injury to alcohol and modifying eff ects: data from two international emergency room projects. Drug Alcohol Depend 82:258- 268.

Cherpitel CJ, Ye Y, Bond J, Borges G, Monteiro M (2015a) Relative risk of injury from acute alcohol consumption: modeling the dose- response relationship in emergency department data from 18 countries. Addiction 110:279- 288.

Cherpitel CJ, Ye Y, Bond J, Borges G, Monteiro M, Chou P, Hao W (2015b) Alcohol attributable fraction for injury morbidity from the doseresponse relationship of acute alcohol consumption: emergency department data from 18 countries. Addiction 110:1724- 1732.

Christophersen AS, Mørland J, Stewart K, Gjerde H (2016) International trends in alcohol and drug use among motor vehicle drivers. Forensic Sci Rev 28:37-66. 
Forson PK, Gardner A, Oduro G, Bonney J, Biney EA, Oppong C, Momade E, Maio RF (2016) Frequency of alcohol use among injure d adult patients presenting to a Ghanaian emergency department. Ann Emerg Med 68:492-500.

Gjerde H, Strand MC, Mørland J (2015) Driving under the influence of nonalcohol drugs- an update. Part I: Epidemiological studies. Forensic Sci Rev 27:89-113.

Gmel GA, Daeppen JB (2007) Recall bias for seven-day recall measurement of alcohol consumption among emergency department patients: implications for case-crossover designs. J Stud Alcohol Drugs 68:303-310.

Houwing S, Hagenzieker M, Mathijssen R, Bernhoft I, Hels T, Janstrup K, Van der Linden T, Legrand S, Verstraete A (2011) Driving under the Influence of Drugs, Alcohol and Medicines Prevalence of alcohol and other psychoactive substances in drivers in generaltraffi c. Part I: General results. Project No. TREN-05-FP6TR-S07.61320-518404-DRUID. Available at: https://biblio.ugent.be/publication/1988541/file/1988562.pdf. Accessed September 3,2017.

Institute for Health Metrics and Evaluation (IHME) (2015) GBD compare. Available at: http://vizhub.healthdata.org/gbd-compare/. Accessed September 3, 2017.

Krager HP, Kazenwadel J, Vollrath M (1995) Grand rapids eff ects revisited: accidents, alcohol and risk. ICADTS 1:S222-S230.

Kuendig H, Hasselberg M, Laflamme L, Daeppen JB, Gmel GA (2008) Acute alcohol consumption and injury: risk associations and attributable fractions for diff erent injury mechanisms. J Stud Alcohol Drugs 69:218- 226

Longo MC, Hunter CE, Lokan RJ, White JM, White MA (2000) The prevalence of alcohol, cannabinoids, benzodiazepines and stimulants amongst injured drivers and their role in driver culpability: Part II: The relationship between drug prevalence and drug concentration, and driver culpability. Accid Anal Prev 32:623- 632.

Maclure M (1991) The case-crossover design: a method for studying transient eff ects on the risk of acute events. Am J Epidemiol 133:144- 153.

Maximus S, Figueroa C, Pham J, Kuncir E, Barrios C (2016) DUI histories in intoxicated injured bicyclists. J Trauma Acute Care Surg 81:638- 643.

Miller TR, Spicer RS (2012) Hospital-admitted injury attributable to alcohol. Alcohol Clin Exp Res 36:104- 112.

Mittleman MA, Maclure M, Robins JM (1995) Control sampling strategies for case-crossover studies: an assessment of relative effi ciency. Am J Epidemiol 142:91-98.

Monteiro M (2007) Alcohol and Public Health in the Americas: A Case for Action. Pan American Health Organization, Washington, DC.

Pan American Health Organization (2013) Prevention of Alcohol-Related Injuries in the Americas: From Evidence to Policy Action. Pan American Health Organization, Washington, DC.

Pan American Health Organization (2015) Regional Status Report on Alcohol and Health in the Americas. Pan American Health Organization, Washington, DC.

Pechansky F, Chandran A (2012) Why don't northern American solutions to drinking and driving work in southern America? Addiction 107:12011206.

Pechansky F, Chandran A, Sousa T (2016) Bridging a historical gap: can changes in perceptions of law enforcement and social deterrence accelerate the prevention of drunk driving in low and middle-income countries? Rev BrasPsiquiatr 38:161- 166.

Pechansky F, De Boni RB, Duarte P (2010) Use of Alcohol and Other Drugs on Brazilian Roads and Other Studies. 1st ed. Digitalcom, Porto Alegre.

du Plessis M, Hlaise KK, Blumenthal R (2016) Ethanol-related death in GaRankuwa road-users, South Africa: a five-year analysis. J Forensic Leg Med 44:5-9.

Poikolainen K, Paljârvi T, Mákela P (2007) Alcohol and the preventive paradox: serious harms and drinking patterns. Addiction 102:571- 578.
Rehm J, Monteiro M, Room R, Gmel GA, Jernigan D, Frick U, Graham K (2001) Steps towards constructing a global comparative risk analysis for alcohol consumption: determining indicators and empirical weights for patterns of drinking, deciding about theoretical minimum, and dealing with diff erent consequences. Eur Addict Res 7:138-147.

Rothman KJ, Greenland S, Lash L (2008) Modern Epidemiology. 3rd ed. Lippincott William \& Wilkins, Philadelphia, PA.

Royston P, Ambler G, Sauerbrei W (1999) The use of fractional polynomials to model continuous risk variables in epidemiology. Int $\mathrm{J}$ Epidemiol 28:964- 974.

Saldanha RF, Pechansky F, Benzano D, Barros CA, Boni RB (2014) Diff er- ences between attendance in emergency care of male and female victims of traffi c accidents in Porto Alegre, Rio Grande do Sul state, Brazil. Cien Saude Colet 19:3925-3930.

Senserrick T, Boufous S, De Rome L, Ivers R, Stevenson M (2014) Detailed analysis of pedestrian casualty collisions in Victoria, Australia. Traffi c Inj Prev 15:S197-S205.

Sethi M, Heyer J, Wall S, DiMaggio C, Shinseki M, Slaughter D, Frangos S (2016) Alcohol use by urban bicyclists is associated with more severe injury, greater hospital resource use, and higher mortality. Alcohol 53:1- 7.

Sousa TRV, Correa E, Stampe MZ, Junior SDSP, De Boni R (2010) Cost of traffi c accidents with victims associated with alcohol use in Porto Alegre, in Use of Alcohol and Other Drugs on Brazilian Roads and Other Studies (Pechansky F, De Boni RB, Duarte P eds) pp 100- 110. Digitalcom, Porto Alegre.

Stata Corp LP (2013) Stata Statistical Software. [Release 13.1]. Stata Corp LP, College Station, TX.

Steenland K, Armstrong B (2006) An overview of methods for calculating the burden of disease due to specific risk factors. Epidemiology 17:512519 .

Strand MC, Gjerde H, Mørland J (2016) Driving under the influence of nonalcohol drugs- an update. Part II: Experimental studies. Forensic Sci Rev 28:79- 101 .

Taylor B, Irving H, Kanteres F, Room R, Borges G, Cherpitel CJ, Greenfield T, Rehm J (2010) The more you drink, the harder you fall: a systematic review and meta-analysis of how acute alcohol consumption and injury or collision risk increase together. Drug Alcohol Depend 110:108116.

Waller P, Stewart J, Hansen A, Stutts J, Popkin C, Rodgman E (1986) The potentiating eff ects of alcohol on driver injury. JAMA 256:1461- 1466.

World Health Organization (2009) Alcohol and Injuries: Emergency Department Studies in an International Perspective. World Health Organization, Geneva.

World Health Organization (2010a) Global Plan for the Decade of Action for Road Safety 2011-2020. World Health Organization, Geneva.

World Health Organization (2010b) Global Strategy to Reduce the Harmful Use of Alcohol. World Health Organization, Geneva.

World Health Organization (2014) Global Status Report on Alcohol and Health 2014. World Health Organization, Geneva.

World Health Organization (2015a) Brasilia Declaration: Second Global High-level Conference on Road Safety: Time for Results Brasilia, 18- 19 November 2015. World Health Organization, Geneva.

World Health Organization (2015b) Global Status Report on Road Safety 2015. World Health Organization, Geneva.

Ye Y, Bond J, Cherpitel CJ, Borges G, Monteiro M, Vallance K (2013a) Evaluating recall bias in a case-crossover design estimating risk of injury related to alcohol: data from six countries. Drug Alcohol Rev 32:512- 518 .

Ye Y, Cherpitel CJ, MacDonald S (2013b) Alcohol-related injuries in the Americas: variation by cause and country, in Prevention of Alcohol-Related Injuries in the Americas: From Evidence to Policy Action (Cherpitel CJ, Borges G, Giesbrecht N, Monteiro M, Stockwell T eds), pp 61-68. Pan American Health Organization, Washington, DC. 